\title{
Influence of voxel size on forest canopy height estimates using full-waveform airborne LiDAR data
}

\author{
Cheng Wang ${ }^{1,2}$, Shezhou Luo ${ }^{1 *}$, Xiaohuan $\mathrm{Xi}^{2}$, Sheng $\mathrm{Nie}^{2}$, Dan Ma ${ }^{1}$ and Youju Huang ${ }^{3}$
}

\begin{abstract}
Background: Forest canopy height is a key forest structure parameter. Precisely estimating forest canopy height is vital to improve forest management and ecological modelling. Compared with discrete-return LiDAR (Light Detection and Ranging), small-footprint full-waveform airborne LiDAR (FWL) techniques have the capability to acquire precise forest structural information. This research mainly focused on the influence of voxel size on forest canopy height estimates.

Methods: A range of voxel sizes (from $10.0 \mathrm{~m}$ to $40.0 \mathrm{~m}$ interval of $2 \mathrm{~m}$ ) were tested to obtain estimation accuracies of forest canopy height with different voxel sizes. In this study, all the waveforms within a voxel size were aggregated into a voxel-based LiDAR waveform, and a range of waveform metrics were calculated using the voxelbased LiDAR waveforms. Then, we established estimation model of forest canopy height using the voxel-based waveform metrics through Random Forest (RF) regression method.

Results and conclusions: The results showed the voxel-based method could reliably estimate forest canopy height using FWL data. In addition, the voxel sizes had an important influence on the estimation accuracies $\left(R^{2}\right.$ ranged from 0.625 to 0.832 ) of forest canopy height. However, the $R^{2}$ values did not monotonically increase or decrease with the increase of voxel size in this study. The best estimation accuracy produced when the voxel size was $18 \mathrm{~m}$ $\left(R^{2}=0.832\right.$, RMSE $\left.=2.57 \mathrm{~m}, \mathrm{RMSE} \%=20.6 \%\right)$. Compared with the lowest estimation accuracy, the $R^{2}$ value had a significant improvement (33.1\%) when using the optimal voxel size. Finally, through the optimal voxel size, we produced the forest canopy height distribution map for this study area using RF regression model. Our findings demonstrate that the optimal voxel size need to be determined for improving estimation accuracy of forest parameter using small-footprint FWL data.
\end{abstract}

Keywords: Voxel size, Airborne LiDAR, Full-waveform, Forests, Canopy height

\section{Background}

Forest ecosystems are key carbon sinks and can affect the climate change and global carbon cycle (Tsui et al. 2013; Zhang et al. 2019). One of the important forest structure parameters is forest canopy height, which is an essential input parameter of ecosystems models and forest management (Popescu and Zhao 2008; Wang et al. 2011). Forest

\footnotetext{
* Correspondence: luoshezhou@163.com

${ }^{1}$ College of Resources and Environment, Fujian Agriculture and Forestry University, Fuzhou 350002, China

Full list of author information is available at the end of the article
}

canopy height is highly correlated with forest above-ground biomass and can be used to quantify the terrestrial carbon cycle (Balzter et al. 2007), and therefore, accurate estimates of forest canopy height are critical to improve ecological modelling and estimates of forest biomass, volume, and productivity. Traditional field-measured methods can obtain accurate tree heights; however, field measurements are laborious and time-consuming with low efficiency. Moreover, field-based methods have difficulty in obtaining continuous tree height data over large areas. Remote sensing techniques can periodically acquire spatial information of 
forest over large areas and are the only feasible approach to estimate vegetation parameters at a series of spatial and temporal scales (García et al. 2010). Remote sensing data are increasingly used to estimate vegetation parameters (e.g., Chopping et al. 2011; Eisfelder et al. 2012; Barrachina et al. 2015; Nie et al. 2017; García et al. 2018). Nevertheless, passive optical remote sensing data, such as multi- and hyperspectral imageries cannot directly obtain vertical structural information of vegetation and are susceptible to weather and complex terrain conditions (Stojanova et al. 2010). In addition, the signal saturation problem of optical remote sensing data easily occurs in dense vegetation areas or high biomass level (Solberg et al. 2017). Although vegetation parameters can be estimated using optical remote sensing data, the estimation precisions usually decline in vegetated areas with high biomass or densely vegetated areas (Duncanson et al. 2010).

LiDAR (Light Detection and Ranging) is an active remote sensing, and LiDAR data have been widely used for predicting vegetation structural parameters, such as canopy height (Maguya et al. 2015; Alexander et al. 2018; Matasci et al. 2018; Mielcarek et al. 2018; Iverson et al. 2019), leaf area index (Alonzo et al. 2015; Zheng et al. 2017), and biomass (Frazer et al. 2011; Montagnoli et al. 2015; Luo et al. 2017; Dalponte et al. 2018; Silva et al. 2018). LiDAR data have a unique ability to predict vegetation canopy height because LiDAR pulses can penetrate the vegetation canopy (Lefsky et al. 2005). LiDAR can be classified as discrete-return LiDAR (DRL) and full-waveform LiDAR (FWL). DRL sensor can record a few (usually less than 5 returns) returns per laser pulse. A series of LiDAR metrics can be calculated using DRL data, which are widely used to predict vegetation structural parameter. However, DRL techniques possess a dead zone about 2.0 or more meters (Rogers et al. 2015). In contrast, FWL systems are able to record all signal returned by illuminated objects (Hermosilla et al. 2014a; Lai and Zheng 2015; Qin et al. 2015), and can overcome the problem of dead zone in DRL systems (Ballhorn et al. 2009). FWL sensors can acquire richer information about ground objects and can precisely characterize the vegetation vertical structure (Sumnall et al. 2016). By processing and analysis of waveform LiDAR data, additional information on forest structure can be extracted, which is not available in discrete-return LiDAR data (Rogers et al. 2015; Pablo et al. 2018).

To take advantage of the information contained in DRL data and improve the applications of LiDAR data, previous researchers have created pseudo-waveform data utilizing DRL data (e.g., Muss et al. 2011; Popescu et al. 2011; Zhou and Qiu 2015; Luo et al. 2019b). The pseudo-waveforms are created by a voxel-based method. In this method, the LiDAR point clouds are partitioned along the vertical and horizontal directions to form the voxels (Pearse et al. 2019). The results indicated that the pseudo-waveforms generated utilizing DRL data are very similar to the authentic LiDAR waveforms. Moreover, the estimation performances of vegetation parameter utilizing pseudo-waveforms are comparable to or better than discrete-return LiDAR data (Muss et al. 2011; Lindberg et al. 2012). With recent development in LiDAR techniques, increasing small-footprint FWL data can be available. There are two approaches to process full-waveform airborne LiDAR data. One approach is extraction of discrete returns from waveform LiDAR data using waveform decomposition method and produces denser point clouds, and then a range of LiDAR statistical metrics are calculated using discrete-return point clouds (Gao et al. 2015; Milenković et al. 2017; Sumnall et al. 2016). Another one is a voxel-based approach. In this approach, all waveforms are converted into a three-dimensional voxel to generate larger scale waveforms (Stelling and Richter 2016). Previous researchers have extracted a series of waveform metrics from voxel-based waveform data and successfully estimated vegetation parameters (Hermosilla et al. 2014b; Li et al. 2016; Nie et al. 2017; Pablo et al. 2018). Hancock et al. (2017) used a voxel-based approach for predicting canopy cover and the results showed that the voxel-based waveforms can obtain more details on understory vegetation and within-canopy structure. Cao et al. (2014) estimated forest biomass utilizing waveform LiDAR metrics and compared predictive power of biomass utilizing DRL metrics and FWL metrics, and they found that fusing DRL metrics and FWL metrics improved prediction accuracy of forest biomass. Pablo et al. (2018) predicted Mediterranean understory vegetation height, cover and volume utilizing FWL and the results indicated that FWL data can accurately estimate understory vegetation parameters.

The scan angle of small-footprint FWL systems is usually off-nadir. Therefore, waveform data for the same position have different paths, which can cause waveforms to fail to precisely depict vertical structural information of vegetation canopy (Hermosilla et al. 2014a). However, the voxel-based approach can decrease the influence of offnadir scan angle. In addition, the voxel-based approach can take full advantage of the information provided by waveforms, which has potential for improving the prediction precision of vegetation parameter. An increasing number of researchers have used a voxel-based method to process FWL data and estimated vegetation parameters. Pang et al. (2011) studied the influence of footprint size of spaceborne waveform LiDAR on the estimation accuracy of canopy height. The results show that the footprint size had a distinct influence on the estimation accuracy of canopy height. Similarly, the voxel sizes of FWL data have an important influence on estimation accuracy of vegetation parameters. As a consequence, it is of great significance to 
obtain the optimal voxel size for improving prediction precision of vegetation parameter. Nevertheless, little research has investigated the influence of voxel sizes on the prediction precision of canopy height. The main objectives of this study were to: (1) create voxel-based LiDAR waveforms with different voxel sizes; (2) estimate forest canopy height using voxel-based LiDAR metrics; and (3) assess the influence of voxel sizes on prediction precison of canopy height and determine the optimal voxel size.

\section{Materials and methods}

\section{Study area}

This study area is located in Huailai County of Hebei Province, North China, which is adjacent to Beijing, the Capital of China. The study area and locations of field plots are shown in Fig. 1. Huailai County is in the semi-arid region. The average precipitation and temperature are 396 mm.year ${ }^{-1}$ and $9.6^{\circ} \mathrm{C}$, respectively. In our study area, the average altitude is $540 \mathrm{~m}$ above sea level with flat terrain. The trees are planted forest and are dominated by poplar (Populus spp.), and the staple crops are corn and soybeans.

\section{Field measurements}

Field-measured data were collected from July 7th to 13th, 2014. Height $(h)$ of each tree in a plot was measured. The center coordinates of all the plots were determined using an RTK-GPS. A total of 34 square plots $(20 \mathrm{~m} \times 20 \mathrm{~m})$ were collected. Canopy height $(H)$ with a plot scale was calculated using Eq. $1 . H$ was between 5.01 and $26.17 \mathrm{~m}$ with mean of $12.49 \mathrm{~m}$ (standard deviation $=5.47 \mathrm{~m}$ ).

$$
H=\frac{\sum_{i=1}^{n} h_{i}}{n}
$$

where $n$ is the number of the tree in a plot; $h_{i}$ is the $h$ of the $i$ th tree in a plot.

\section{Full-waveform LiDAR data acquisition}

Full-waveform airborne LiDAR data were collected on July 27th, 2014 utilizing the Leica ALS70-HA LiDAR sensor. The absolute flight height was $2800 \mathrm{~m}$ with scan angle of $\pm 12^{\circ}$. The flight stripe side lap was $50 \%$ with an average pulse density of 4.1 pulses $\mathrm{m}^{-2}$. LiDAR data acquisition parameters are shown in Table 1. In addition, discrete-return LiDAR data were also provided by the LiDAR vendor. Discrete-return point clouds were classified as ground and non-ground laser points through Terrasolid software. And then, ground laser points were

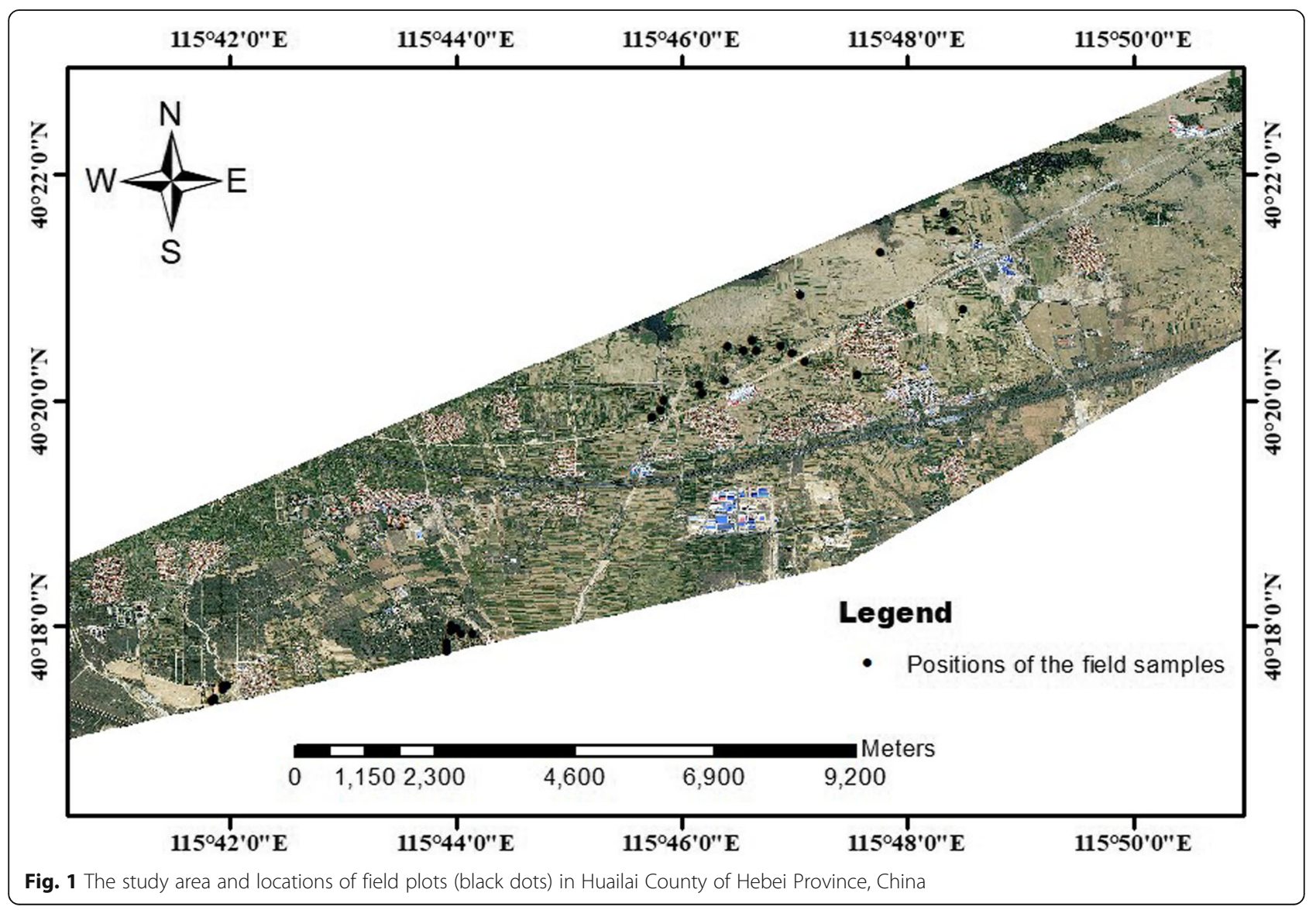


Table 1 LiDAR data acquisition parameters

\begin{tabular}{ll}
\hline Parameters & Specification \\
\hline Absolute flying height & $2800 \mathrm{~m}$ \\
Flying speed & $92 \mathrm{~m} \cdot \mathrm{s}^{-1}$ \\
Scan angle & $\pm 12^{\circ}$ \\
Wavelength & $1064 \mathrm{~nm}$ \\
Beam divergence & $0.15 \mathrm{mrad}$ \\
Swath overlap & $50 \%$ \\
\hline
\end{tabular}

interpolated into $0.5 \mathrm{~m}$ resolution DTM (Digital Terrain Model).

\section{LiDAR data processing}

\section{Pre-processing of full-waveform LiDAR data}

Waveform data processing includes denoising, attenuation correction, waveform heights normalization, and so on. Figure 2 provides an overview of full-waveform LiDAR data processing and forest canopy height estimation. The main purposes of data pre-processing are to remove the noise in waveform data and correct the attenuation of waveform signal. To enhance the signalto-noise ratio (SNR) of waveform data and get the real waveform signal, we removed the noise using a noise threshold method. The threshold was determined using the mean plus four standard deviations in our study (Lefsky et al. 2007), and all the waveform signals below the threshold were removed as the noise. And then, the waveform data were smoothed using a Gaussian filter.
Moreover, the heights of LiDAR waveforms were normalized using the DTM. To reduce the effects of attenuation produced by the upper canopy, all waveform intensities were rectified utilizing an approach presented by Richter et al. (2014).

\section{Waveform voxelization}

The voxel-based waveforms can reduce the spatial displacement caused by the off-nadir scan angles (Pablo et al. 2018) and can characterize the fine-scale vertical structural information of vegetation canopy. In our study, we voxelized the pre-processed waveform LiDAR data using a series of voxel sizes. The horizontal sizes of voxel were from 10.0 to $40.0 \mathrm{~m}$ interval of $2 \mathrm{~m}$ and the vertical size of voxel was set to a constant of $0.15 \mathrm{~m}$. And then, all voxels were assigned the mean intensity of all waveforms falling within a voxel space.

\section{Voxel-based waveform metrics}

To estimate forest canopy height, a series of waveform metrics were extracted utilizing voxel-based waveform LiDAR data. Commonly used waveform metrics include the waveform distance (WD), height of median energy (HOME) (Drake et al. 2002), HTRT (ratio of WD to HOME), vertical distribution ratio (VDR), front slope angle (FS) (Ranson et al. 2004), etc. See reference (Luo et al. 2019a) for more waveform metrics and descriptions. To obtain accurate waveform feature information, voxel-based waveforms were decomposed using a Gaussian decomposition approach. In

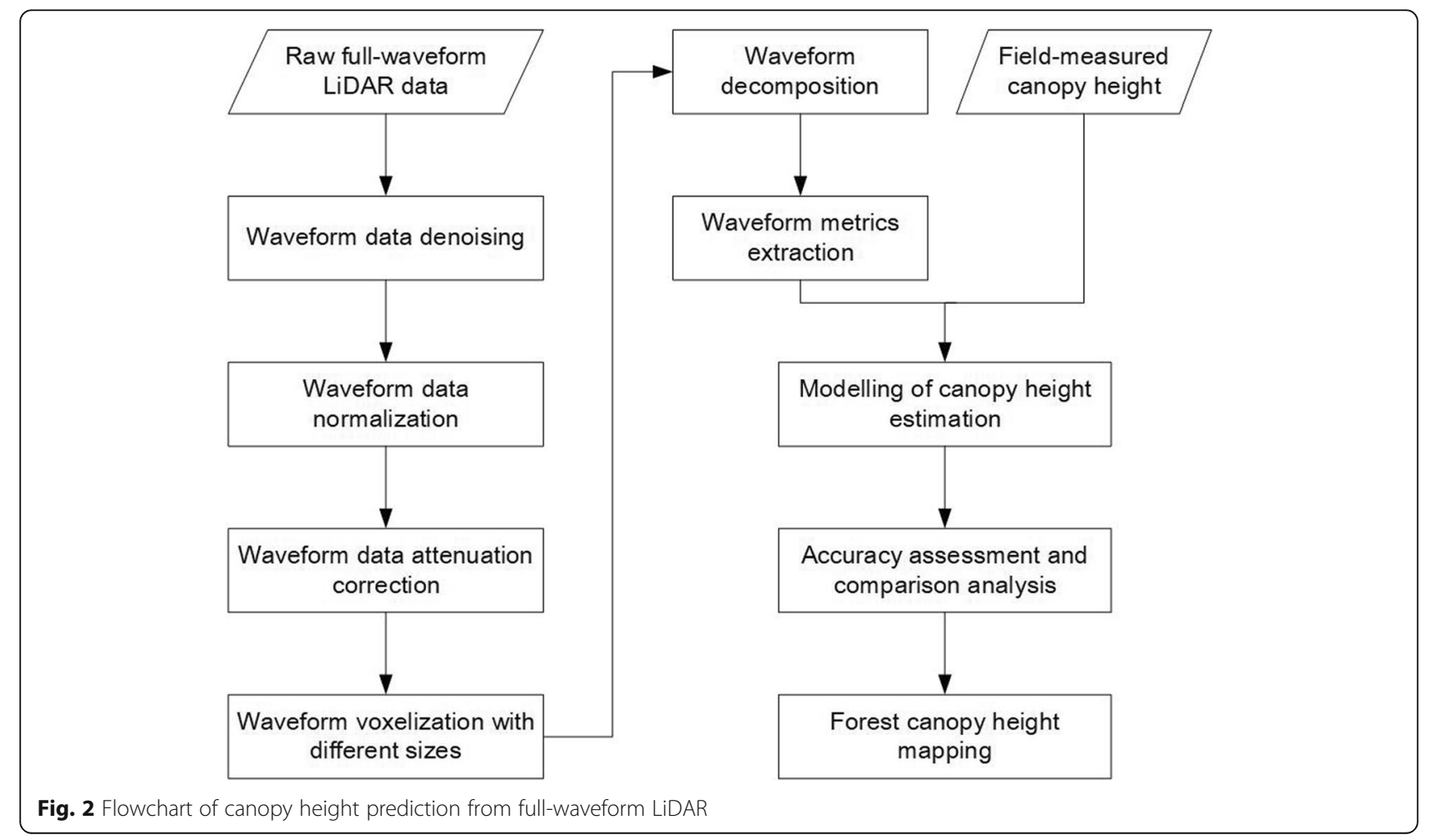


our research, the last Gaussian curve represents ground signal (Popescu et al. 2011).

\section{Statistical analyses and modelling}

In the research, Random Forest (RF) algorithm was used to estimate forest canopy height. RF does not need any assumption about data distribution and can solve complex relationships between waveform metrics and canopy height (Ahmed et al. 2015). RF algorithm has the ability to overcome overfitting and improve prediction precision of forest canopy height (Pearse et al. 2019). In addition, RF regression produces unbiased estimates and does not need independent validation for estimation model (Breiman 2001; Naidoo et al. 2012), and this is especially beneficial when no additional validation dataset is available in a study. Therefore, RF regression has been broadly applied for prediction of vegetation parameters in previous studies (Gleason and Im 2012; Ramoelo
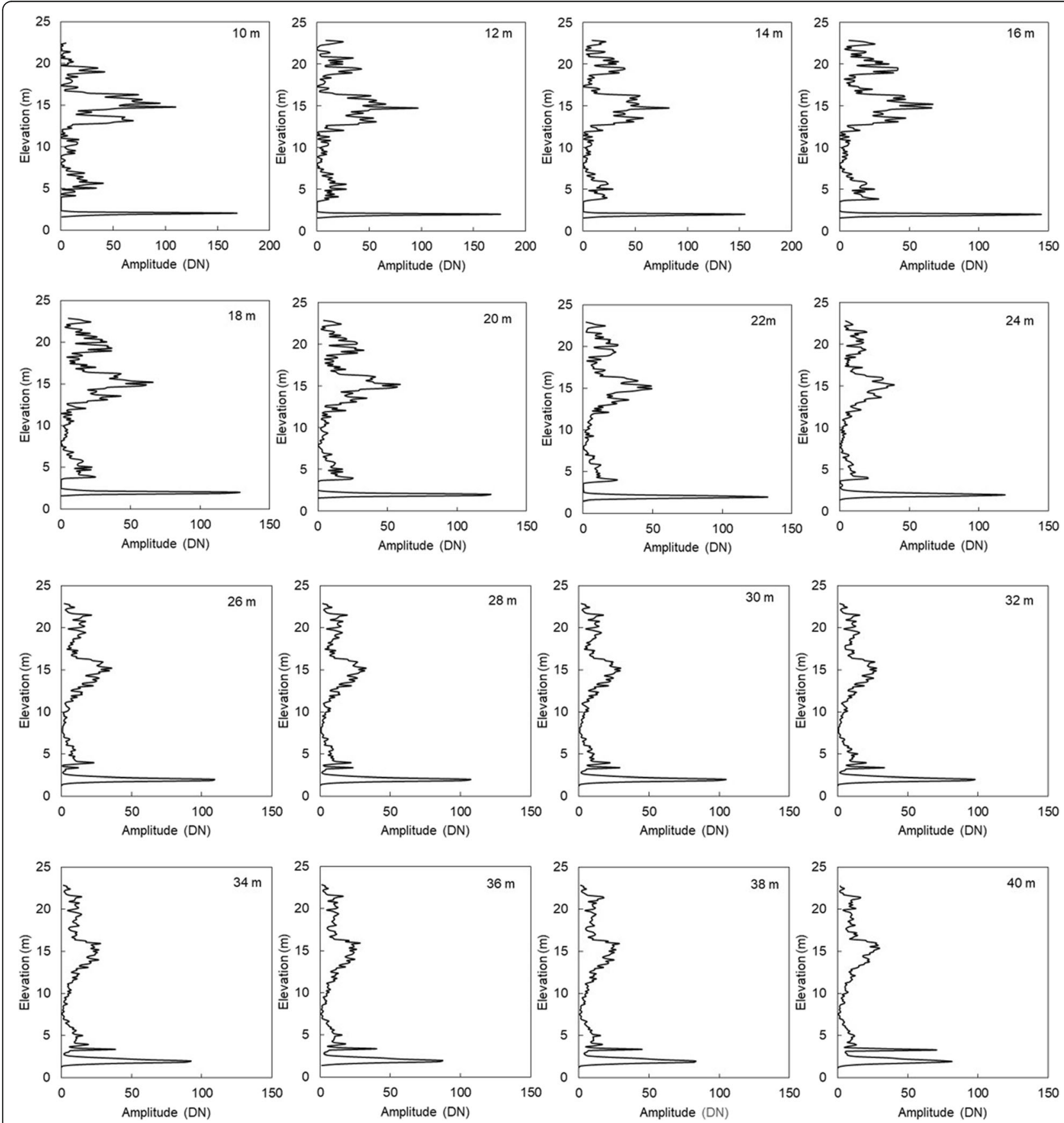

Fig. 3 LiDAR waveforms derived from 16 different voxel sizes (from 10.0 to $40.0 \mathrm{~m}$ interval of $2 \mathrm{~m}$ ) 
et al. 2015; Luo et al. 2018; Zhao et al. 2018). In this study, coefficient of determination $\left(R^{2}\right)$, residual (Eq. 2), root mean squared error (RMSE) (Eq. 2), and relative RMSE (RMSE\%) (Eq. 4) were calculated to validate the estimation accuracy of canopy height.

$$
\begin{aligned}
& \text { residual }=y_{i}-\hat{y}_{i} \\
& \text { RMSE }=\sqrt{\frac{\sum_{i=1}^{n}\left(y_{i}-\hat{y}_{i}\right)^{2}}{n}} \\
& \text { RMSE } \%=\frac{\text { RMSE }}{\bar{y}} \times 100 \%
\end{aligned}
$$

where $y_{i}$ and $\hat{y}_{i}$ represent the observed and predicted forest canopy height on the sample plot $i$, respectively; $\bar{y}$ is the average value of observations and $n$ is the total number of plots.

\section{Results}

LiDAR waveform data with 16 different voxel sizes were produced through aggregating all the waveforms in a voxel. Figure 3 presents the LiDAR waveforms of 16 voxel sizes for the same field plot. The results show that the voxel-based method could successfully produce new LiDAR waveforms utilizing full-waveform LiDAR data. In addition, there were some differences among LiDAR waveforms for the different voxel sizes (Fig. 3), which could cause the difference of prediction precision of vegetation structure parameter. Figure 4 shows the voxel-based waveform, five Gaussian curves derived

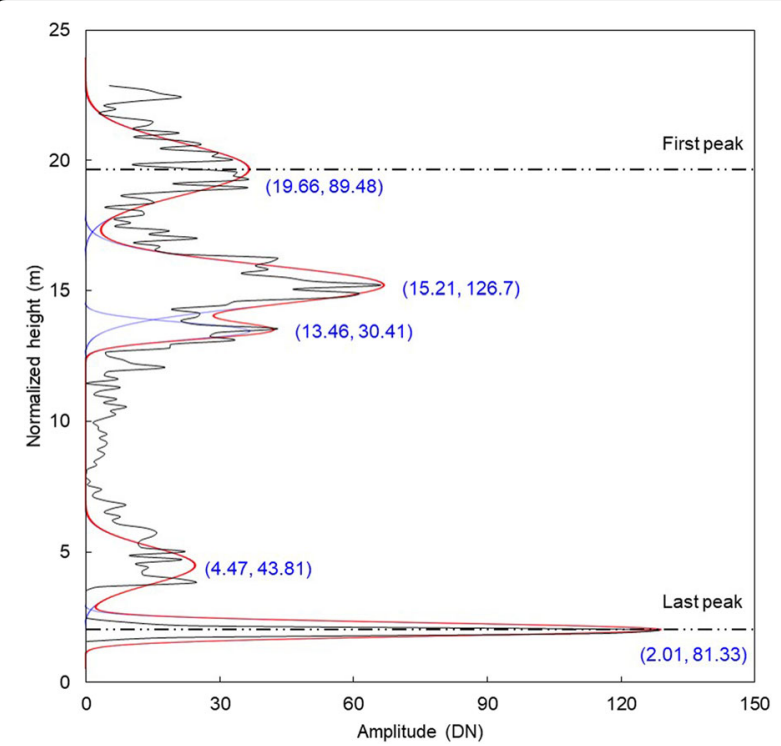

Fig. 4 Voxel-based LiDAR waveform, fitted curve, five Gaussian curves. The center position and area of Gaussian curve are listed in brackets using the Gaussian decomposition approach and their center positions. The voxel-based waveform was decomposed into five Gaussian components (four canopy components and one ground component) (Fig. 4). And then, the voxel-based waveform metrics were calculated using the parameters of Gaussian curves.

Prediction precisions of forest canopy height with different voxel sizes are shown in Fig. 5. Figure 6 shows the influences of voxel sizes (from 10.0 to $40.0 \mathrm{~m}$ interval of $2 \mathrm{~m}$ ) on prediction precisions of canopy height. In this study, the voxel sizes from 16 to $38 \mathrm{~m}$ can be used as appropriate voxel size to estimate forest canopy height, and all $R^{2}$ values were greater than or equal to 0.768 . The highest $R^{2}$ was 0.832 with $\mathrm{RMSE}=2.57 \mathrm{~m}$ $($ RMSE\% $=20.6 \%)$, which was produced at the voxel size of $18 \mathrm{~m}$. The scatter plot of field-measured forest canopy height against estimated height using the optimal voxel size is presented in Fig. 7b. Orange area represents 95\% confidence interval and red solid line is fit line. Compared with the $R^{2}$ values derived from the minimum voxel size $(10 \mathrm{~m})\left(R^{2}=0.625\right.$, Fig. $\left.7 \mathrm{a}\right)$ and the maximum voxel size $(40 \mathrm{~m})\left(R^{2}=0.75\right.$, Fig. $\left.7 \mathrm{c}\right)$, the $R^{2}$ value derived from the optimal voxel size of $18 \mathrm{~m}$ improved by $33.1 \%$ and $10.9 \%$, respectively. In short, forest canopy height could be reliably estimated by a voxel-based method utilizing full-waveform data. In addition, voxel sizes had important influences on prediction accuracy of canopy height. Therefore, when predicting canopy height utilizing LiDAR waveform metrics, it is necessary to determine the optimal voxel size to improve estimation accuracy. In this study, we also estimated canopy heights using discrete-return metrics with the optimal voxel size. Figure 8 shows the scatterplot of field-measured canopy heights against estimated values. To highlight the advantage of waveform data for estimating canopy height, we compared the results derived from waveform metrics with the results derived from discrete-return metrics. The results show that waveform metrics can produce better estimation accuracy than discrete-return metrics, although the $R^{2}$ only improved by $3 \%$. The map of canopy height in the study area was produced using waveform data based on the optimal voxel size of $18 \mathrm{~m}$ (Fig. 9).

\section{Discussion}

This research demonstrated how to predict canopy height utilizing a voxel-based approach from waveform data. The voxel-based approach has previously been applied to predict vegetation structure parameter. Our results showed that the voxel-based method is an effective method to estimate vegetation parameters, which could precisely estimate forest canopy height using fullwaveform LiDAR data. Similar findings were observed in previous studies (Popescu and Zhao 2008; Allouis et al. 


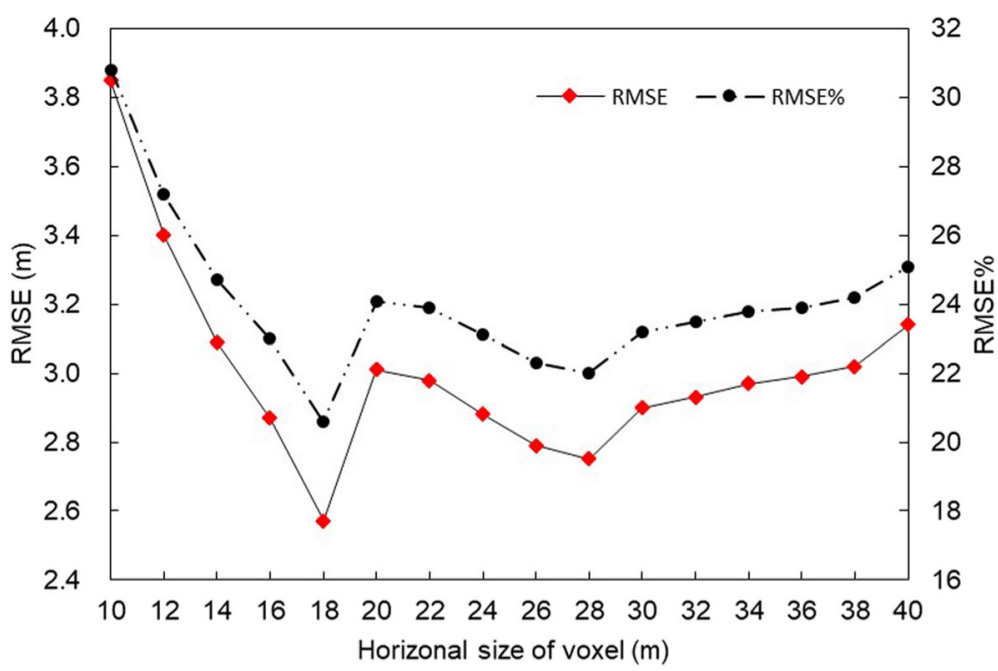

Fig. 5 Prediction precisions of forest canopy height with different voxel sizes

2013; Pablo et al. 2018; Pearse et al. 2019). However, little research has explored the effect of voxel sizes on the estimation accuracy of vegetation parameter, especially for waveform data. Our research primarily focused on exploring the influence of voxel size on forest canopy height estimates from waveform LiDAR. We used a series of voxel sizes (from 10.0 to $40.0 \mathrm{~m}$ interval of $2 \mathrm{~m}$ ) to produce voxel-based waveform data. The results indicated that voxel-based waveforms with different voxel sizes could be reliably created utilizing mean value of all waveform intensities falling in each voxel. Although 16 waveforms with different voxel sizes were generally similar (Fig. 3), there were small differences among these waveforms. Therefore, waveform metrics extracted from voxel-based waveforms with different voxel sizes also had some differences, which could result in different estimation accuracies of canopy height.
In the research, waveform metrics were extracted from voxel-based waveform to predict canopy height. In our study, all 34 field-measured plots were used for modelling, and there are no additional plots for separate validation. Because RF regression algorithm can avoid the need for independent validation using out-of-bag method, we used RF regression to successfully establish 16 estimation models through voxel-based waveform metrics with different voxel sizes. We found that voxel-based waveform metrics were able to accurately estimate forest canopy height (the best result was $R^{2}=0.832$ with $\mathrm{RMSE}=2.57 \mathrm{~m}$ ) (Fig. 7b). Figure 10 shows residuals distribution of estimated forest canopy height against field-measured height. In general, residuals for canopy height estimates are reasonable, although the canopy heights were underestimated for the canopy heights greater than $17 \mathrm{~m}$.

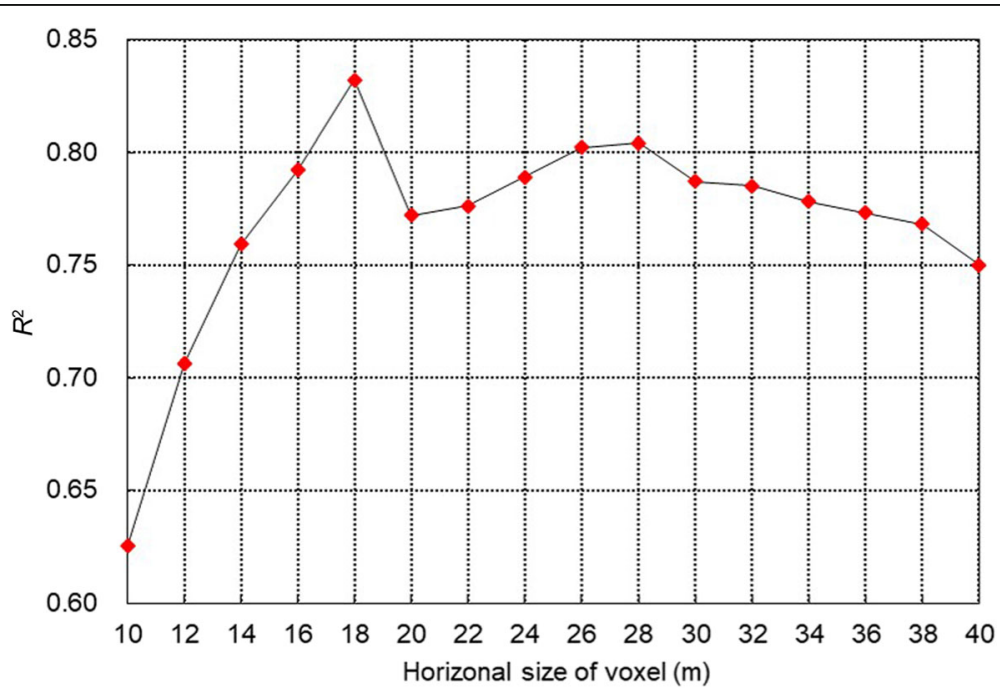

Fig. 6 Influences of voxel sizes (from 10.0 to 40.0 m interval of 2 m) on the estimation accuracies of forest canopy height 

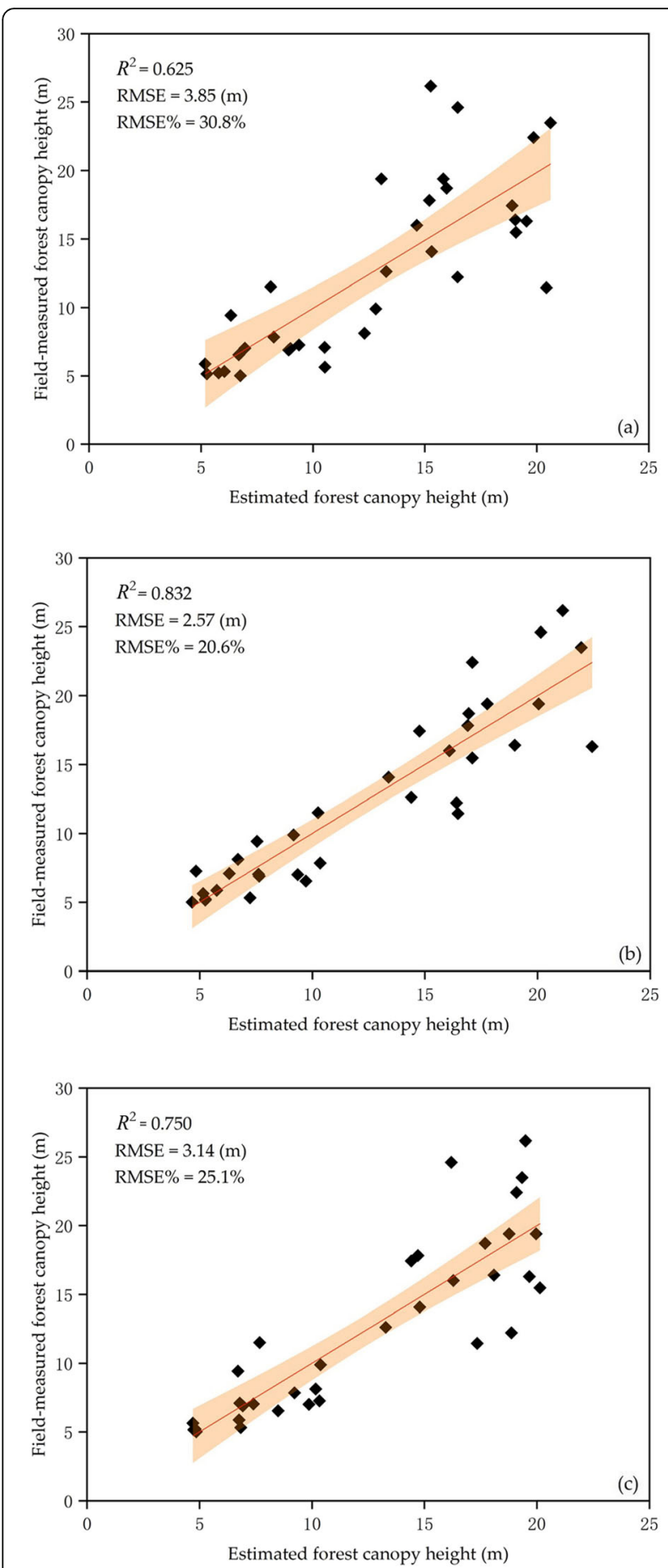

Fig. 7 Scatterplots of field-measured forest canopy heights against estimated values using (a) the minimum voxel size of $10 \mathrm{~m} \times 10 \mathrm{~m}$, (b) the optimal voxel size $(18 \mathrm{~m} \times 18 \mathrm{~m})$ and $(\mathbf{c})$ the maximum voxel size of $40 \mathrm{~m} \times 40 \mathrm{~m}$. Orange area represents $95 \%$ confidence interval. Red solid line is fit line

The variations of $R^{2}$ values with voxel sizes are shown in Fig. 6, and the results showed that the voxel size had an important effect on estimation accuracy. This finding

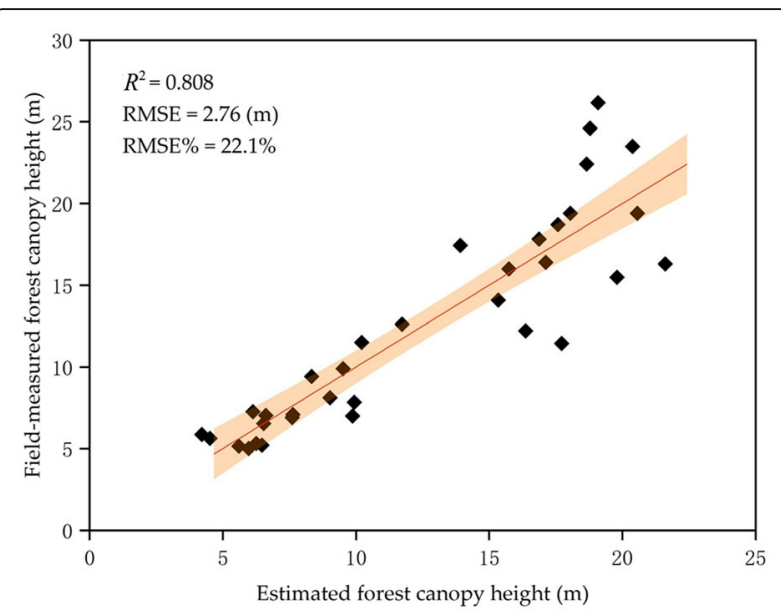

Fig. 8 Scatterplot of field-measured forest canopy heights against estimated values using discrete-return data. Orange area represents 95\% confidence interval. Red solid line is fit line

is consistent with that of Zheng et al. (2017), who performed a sensitivity analysis of voxel sizes $(0.1-26 \mathrm{~m})$ on directional gap fraction, and the results showed that voxel size is a key factor in estimating the directional gap fraction using LiDAR data. Similar results also were reported by Cifuentes et al. (2014), who found that voxel size has noticeable effect on estimation result of gap fraction. In the research, the prediction accuracy of canopy height did not increase or decrease monotonously with an increase of voxel size. When the voxel size was less than $16 \mathrm{~m}$, the estimation accuracy was relatively low. This is because the voxel size is too small to effectively characterize true forest canopy height. Therefore, voxel size should be appropriately increased to produce reliable estimation results. When the voxel size was greater than or equal to $16 \mathrm{~m}$, the estimation accuracy was not significantly different. Therefore, the larger the voxel size was used, the more stable and precise estimation accuracy was produced. This is due to the fact that larger voxel size contains more waveforms, which can more effectively characterize the vertical structure of vegetation. Similar findings were reported by CrespoPeremarch and Ruiz (2018), and they found that the voxel size should be appropriately increased to keep reliable biomass estimation accuracy, especially using low pulse density LiDAR data.

This study showed that voxel sizes from 16 to $38 \mathrm{~m}$ could be identified as appropriate voxel sizes to estimate forest canopy height, and all $R^{2}$ values were greater than or equal to 0.768 . Nevertheless, there was an optimal voxel size of $18 \mathrm{~m}$, which produced the best estimation result (Fig. $7 \mathrm{~b}$ ). We found that the optimal voxel size was not consistent with field-measured plot size. This is because the voxel size of $18 \mathrm{~m}$ could better describe the characteristics of forest canopy height in the study area. 


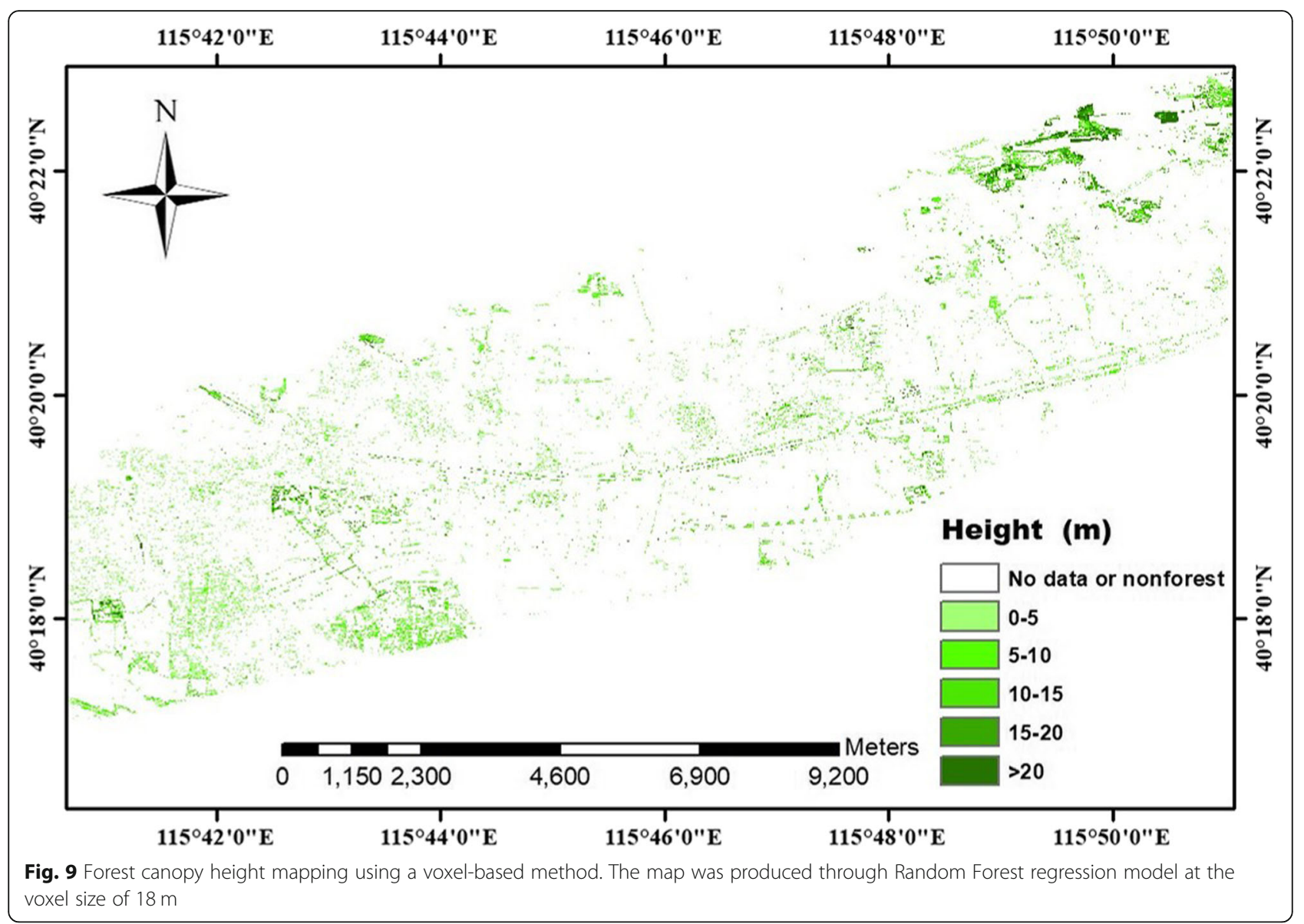

Kim et al. (2016) found that prediction accuracy of forest biomass could improve by $27.8 \%$ using the voxel size of $30 \mathrm{~m} \times 30 \mathrm{~m}$ than using the voxel size of $20 \mathrm{~m} \times 20 \mathrm{~m}$. Almeida et al. (2019) studied the influences of voxel sizes $(1,2,5,10,25,50$ and $100 \mathrm{~m})$ on leaf area profile estimates, and the results showed that appropriate voxel size could provide reliable estimates of leaf area profile. Compared with the lowest $R^{2}$ value $(0.625$, produced at the voxel size of $10 \mathrm{~m}$ ), the $R^{2}$ value derived from the optimal voxel size improved by $33.1 \%$ in this study. Therefore, our results further demonstrate that the appropriate voxel size can improve estimates of vegetation parameters.

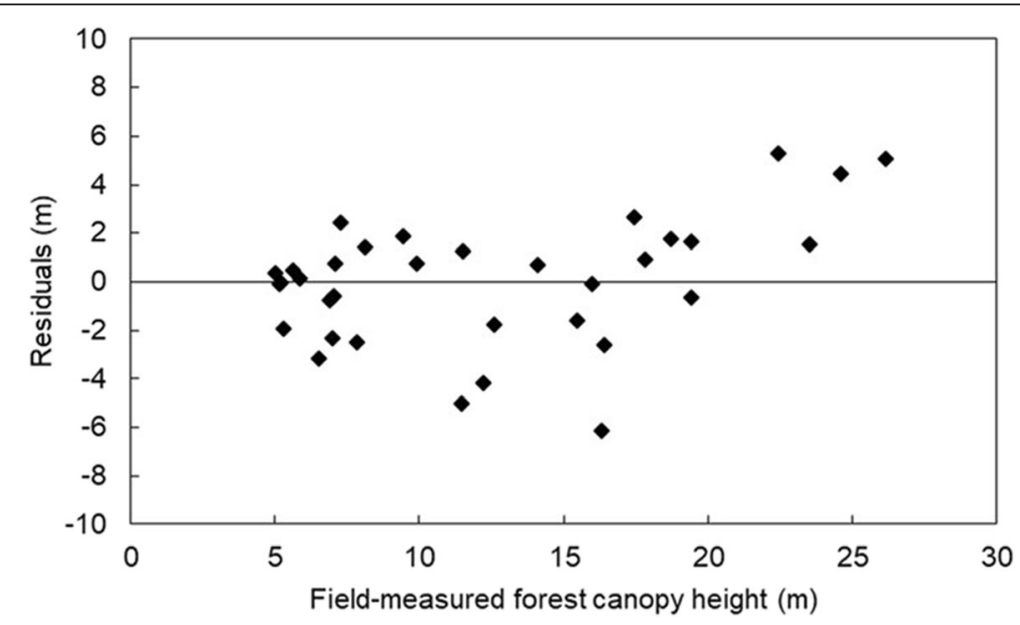

Fig. 10 Residuals distribution of estimated forest canopy heights based on the optimal voxel size $(18 \mathrm{~m} \times 18 \mathrm{~m})$ against field-measured canopy heights 
There are two reasons why the optimal voxel size should be considered while predicting vegetation structure parameter from waveform LiDAR. The first reason is that the optimal voxel size is able to improve prediction precision of vegetation structure parameter. The second is that the optimal voxel size can be used as the guidance for the choice of plot size in field measurements, which helps to improve the efficiency of forest survey. As a consequence, the optimal voxel size should be applied for improving prediction precision of vegetation structure parameter. However, the optimal voxel size may be different for the different research objectives and study areas. Therefore, the optimal voxel size should be determined based on specific vegetation type, estimation parameter, waveform density, terrain, etc. To conclude, the method developed in our study has potential to improve prediction precision of vegetation structure parameter from waveform data.

\section{Conclusions}

In this study, forest canopy heights were predicted from small-footprint full-waveform airborne LiDAR through the voxel-based approach. The results show that the voxel-based method can reliably estimate canopy height from waveform LiDAR (the highest accuracy was $R^{2}=$ 0.832 with $R M S E=2.57 \mathrm{~m}$ ). The influence of voxel sizes on prediction precision of canopy height was carried out. This research demonstrates that the voxel sizes have an important influence on prediction precision of canopy height, and the highest prediction precision was produced when using the voxel size of $18 \mathrm{~m}$. As a consequence, appropriate voxel size can effectively improve estimates of forest parameters, and the optimal voxel size should be determined to obtain the most accurate estimation accuracy of vegetation parameters. Further studies are needed to conduct the effect of voxel sizes on the estimation accuracy of other vegetation types and structural parameters. In addition, in our study the vertical size of voxel was set to a constant of $0.15 \mathrm{~m}$. However, the vertical size of voxel has an influence on prediction precision of vegetation structure parameters. Therefore, different vertical sizes of voxel should be also considered when using a voxel-based approach for predicting vegetation structure parameters.

\section{Acknowledgements \\ The authors would like to thank the anonymous reviewers for their thoughtful comments and suggestions on the manuscript.}

\section{Authors' contributions}

$S L$ designed the study, processed the data and analyzed the results. CW and $\mathrm{SL}$ performed data analysis and wrote the manuscript. XX, SN, DM and $\mathrm{YH}$ collected the data. All authors revised and approved the final manuscript.

\section{Funding}

This research was funded by the Guangxi Natural Science Fund for Innovation Research Team (No. 2019JJF50001), the Natural Science
Foundation of Fujian Province, China (No. 2019 J01396), the Special Fund for Guangxi Innovation and Driving Development (Major science and technology projects) (No. 2018AA13005) and the Youth Innovation Promotion Association CAS (2019130).

Availability of data and materials

Data are available from the corresponding author on reasonable request.

Ethics approval and consent to participate

Not applicable.

Consent for publication

Not applicable.

\section{Competing interests}

The authors declare that they have no competing interests.

\section{Author details}

${ }^{1}$ College of Resources and Environment, Fujian Agriculture and Forestry University, Fuzhou 350002, China. ${ }^{2}$ Key Laboratory of Digital Earth Science, Institute of Remote Sensing and Digital Earth, Chinese Academy of Sciences, Beijing 100094, China. ${ }^{3}$ Guangxi Zhuang Autonomous Region Institute of Natural Resources Remote Sensing, Nanning 530023, China.

Received: 20 October 2019 Accepted: 24 April 2020

Published online: 07 May 2020

\section{References}

Ahmed OS, Franklin SE, Wulder MA, White JC (2015) Characterizing stand-level forest canopy cover and height using Landsat time series, samples of airborne LiDAR, and the random Forest algorithm. ISPRS 101:89-101

Alexander C, Korstjens AH, Hill RA (2018) Influence of micro-topography and crown characteristics on tree height estimations in tropical forests based on LiDAR canopy height models. Int J Appl Earth Obs Geoinf 65:105-113

Allouis T, Durrieu S, Vega C, Couteron P (2013) Stem volume and above-ground biomass estimation of individual pine trees from LiDAR data: contribution of full-waveform signals. IEEE J Sel Topics Appl Earth Observ Remote Sens 6(2): 924-934

Almeida DRA, Stark SC, Shao G, Schietti J, Nelson BW, Silva CA, Gorgens EB, Valbuena R, Papa DA, Brancalion PHS (2019) Optimizing the remote detection of tropical rainforest structure with airborne Lidar: leaf area profile sensitivity to pulse density and spatial sampling. Remote Sens 11(1):92. https://doi.org/10.3390/rs11010092.

Alonzo M, Bookhagen B, McFadden JP, Sun A, Roberts DA (2015) Mapping urban forest leaf area index with airborne lidar using penetration metrics and allometry. Remote Sens Environ 162:141-153

Ballhorn U, Siegert F, Mason M, Limin S (2009) Derivation of burn scar depths and estimation of carbon emissions with LiDAR in Indonesian peatlands. Proc Natl Acad Sci U S A 106(50):21213-21218

Balzter H, Rowland C, Saich P (2007) Forest canopy height and carbon estimation at monks wood National Nature Reserve, UK, using dual-wavelength SAR interferometry. Remote Sens Environ 108(3):224-239

Barrachina M, Cristóbal J, Tulla AF (2015) Estimating above-ground biomass on mountain meadows and pastures through remote sensing. Int J Appl Earth Obs Geoinf 38:184-192

Breiman L (2001) Random forests. Mach Learn 45:5-32

Cao L, Coops NC, Hermosilla T, Innes J, Dai JS, She GH (2014) Using smallfootprint discrete and full-waveform airborne LiDAR metrics to estimate total biomass and biomass components in subtropical forests. Remote Sens 6(8): $7110-7135$

Chopping M, Schaaf CB, Zhao F, Wang ZS, Nolin AW, Moisen GG, Martonchik JV, Bull M (2011) Forest structure and aboveground biomass in the southwestern United States from MODIS and MISR. Remote Sens Environ 115(11):2943-2953

Cifuentes R, van der Zande D, Farifteh J, Salas C, Coppin P (2014) Effects of voxel size and sampling setup on the estimation of forest canopy gap fraction from terrestrial laser scanning data. Agric For Meteorol 194:230-240

Crespo-Peremarch P, Ruiz LA (2018) Influence of Lidar full-waveform density and voxel size on forest stand estimates. IGARSS 2018 International geoscience and remote sensing symposium, Valencia 
Dalponte M, Frizzera L, Orka HO, Gobakken T, Naesset E, Gianell D (2018) Predicting stem diameters and aboveground biomass of individual trees using remote sensing data. Ecol Indic 85:367-376

Drake JB, Dubayah RO, Clark DB, Knox RG, Blair JB, Hofton MA, Chazdon RL, Weishampel JF, Prince SD (2002) Estimation of tropical forest structural characteristics using large-footprint lidar. Remote Sens Environ 79(2):305-319

Duncanson LI, Niemann KO, Wulder MA (2010) Estimating forest canopy height and terrain relief from GLAS waveform metrics. Remote Sens Environ 114 138-154

Eisfelder C, Kuenzer C, Dech S (2012) Derivation of biomass information for semiarid areas using remote-sensing data. Int J Remote Sens 33(9):2937-2984

Frazer GW, Magnussen S, Wulder MA, Niemann KO (2011) Simulated impact of sample plot size and co-registration error on the accuracy and uncertainty of LiDAR-derived estimates of forest stand biomass. Remote Sens Environ 115(2):636-649

Gao S, Niu Z, Sun G, Zhao D, Jia K, Qin YC (2015) Height extraction of maize using airborne full-waveform LiDAR data and a deconvolution algorithm. IEEE Geosci Remote Sens Lett 12(9):1978-1982

García M, Riaño D, Chuvieco E, Danson FM (2010) Estimating biomass carbon stocks for a Mediterranean forest in Central Spain using LiDAR height and intensity data. Remote Sens Environ 114(4):816-830

García M, Saatchi S, Ustin S, Balzter H (2018) Modelling forest canopy height by integrating airborne LiDAR samples with satellite radar and multispectral imagery. Int J Appl Earth Obs Geoinf 66:159-173

Gleason CJ, Im J (2012) Forest biomass estimation from airborne LiDAR data using machine learning approaches. Remote Sens Environ 125:80-91

Hancock S, Anderson K, Disney M, Gaston KJ (2017) Measurement of fine-spatialresolution 3D vegetation structure with airborne waveform lidar: calibration and validation with voxelised terrestrial lidar. Remote Sens Environ 188:37-50

Hermosilla T, Coops NC, Ruiz LA, Moskal LM (2014a) Deriving pseudo-vertical waveforms from small-footprint full-waveform LiDAR data. Remote Sens Lett 5(4):332-341

Hermosilla T, Ruiz LA, Kazakova AN, Coops NC, Moskal LM (2014b) Estimation of forest structure and canopy fuel parameters from small-footprint fullwaveform LiDAR data. Int J Wildland Fire 23(2):224-233. https://doi.org/10. 1071/wf13086

Iverson LR, Rebbeck J, Peters MP, Hutchinson T, Fox T (2019) Predicting Ailanthus altissima presence across a managed forest landscape in Southeast Ohio. For Ecosyst 6(1):41. https://doi.org/10.1186/s40663-019-0198-7

Kim E, Lee WK, Yoon M, Lee JY, Son Y, Abu Salim K (2016) Estimation of voxelbased above-ground biomass using airborne LiDAR data in an intact tropical rain forest, Brunei. Forests 7(11):259. https://doi.org/10.3390/f7110259

Lai X, Zheng M (2015) A denoising method for LiDAr full-waveform data. Mathem Prob Engineer. https://doi.org/10.1155/2015/164318

Lefsky MA, Harding DJ, Keller M, Cohen WB, Carabajal CC, Espirito-Santo FD, Hunter MO, de Oliveira R, de Camargo PB (2005) Estimates of forest canopy height and aboveground biomass using ICESat. Geophys Res Lett 32(22). https://doi.org/10.1029/2005gl025518

Lefsky MA, Keller M, Panga Y, de Camargo PB, Hunter MO (2007) Revised method for forest canopy height estimation from geoscience laser altimeter system waveforms. J Appl Remote Sens 1(1): 013537. https://doi.org/10.1117/1. 2795724

Li W, Niu Z, Li J, Chen HY, Gao S, Wu MQ, Li D (2016) Generating pseudo large footprint waveforms from small footprint full-waveform airborne LiDAR data for the layered retrieval of LAl in orchards. Opt Express 24(9):10142-10156

Lindberg E, Olofsson K, Holmgren J, Olsson H (2012) Estimation of 3D vegetation structure from waveform and discrete return airborne laser scanning data. Remote Sens Environ 118:151-161

Luo S, Chen M, Wang C, Gonsamo A, Xi XH, Lin Y, Qian MJ, Peng DL, Nie S, Qin HM (2018) Comparative performances of airborne LiDAR height and intensity data for leaf area index estimation. IEEE J Sel Topics Appl Earth Observ Remote Sens 11(1):300-310

Luo SZ, Wang C, Xi XH, Nie S, Fan XY, Chen HY, Ma D, Liu JF, Zou J, Lin Y, Zhou GQ (2019a) Estimating forest aboveground biomass using small-footprint fullwaveform airborne LiDAR data. Int J Appl Earth Obs Geoinf 83:101922. https://doi.org/10.1016/j.jag.2019.101922

Luo SZ, Wang C, Xi XH, Nie S, Fan XY, Chen HY, Yang XB, Peng DL, Lin Y, Zhou GQ (2019b) Combining hyperspectral imagery and LiDAR pseudo-waveform for predicting crop LAl, canopy height and above-ground biomass. Ecol Indic 102:801-812
Luo SZ, Wang C, Xi XH, Pan FF, Qian MJ, Peng DL, Nie S, Qin HM, Lin Y (2017) Retrieving aboveground biomass of wetland Phragmites australis (common reed) using a combination of airborne discrete-return LiDAR and hyperspectral data. Int J Appl Earth Obs Geoinf 58:107-117

Maguya AS, Tegel K, Junttila V, Kauranne T, Korhonen M, Burns J, Leppanen V, Sanz B (2015) Moving voxel method for estimating canopy base height from. Airborne laser scanner data 7(7):8950-8972

Matasci G, Coops NC, Williams DAR, Page N (2018) Mapping tree canopies in urban environments using airborne laser scanning (ALS): a Vancouver case study. For Ecosyst 5(1):31. https://doi.org/10.1186/s40663-018-0146-y

Mielcarek M, Stereńczak K, Khosravipour A (2018) Testing and evaluating different LiDAR-derived canopy height model generation methods for tree height estimation. Int J Appl Earth Obs Geoinf 71:132-143

Milenković M, Wagner W, Quast R, Hollaus M, Ressl C, Pfeifer N (2017) Total canopy transmittance estimated from small-footprint, full-waveform airborne LiDAR. ISPRS 128:61-72

Montagnoli A, Fusco S, Terzaghi M, Kirschbaum A, Pflugmacher D, Cohen WB, Scippa GS, Chiatante D (2015) Estimating forest aboveground biomass by low density lidar data in mixed broad-leaved forests in the Italian pre-Alps. For Ecosyst 2(1):10. https://doi.org/10.1186/s40663-015-0035-6

Muss JD, Mladenoff DJ, Townsend PA (2011) A pseudo-waveform technique to assess forest structure using discrete lidar data. Remote Sens Environ 115(3): 824-835

Naidoo L, Cho MA, Mathieu R, Asner G (2012) Classification of savanna tree species, in the greater Kruger National Park region, by integrating hyperspectral and LiDAR data in a random Forest data mining environment. ISPRS 69:167-179

Nie S, Wang C, Zeng H, Xi X, Li G (2017) Above-ground biomass estimation using airborne discrete-return and full-waveform LiDAR data in a coniferous forest. Ecol Indic 78:221-228

Pablo CP, Piotr T, Nicholas C, Angel RL (2018) Characterizing understory vegetation in Mediterranean forests using full-waveform airborne laser scanning data. Remote Sens Environ 217:400-413

Pang Y, Lefsky M, Sun G, Ranson J (2011) Impact of footprint diameter and offnadir pointing on the precision of canopy height estimates from spaceborne lidar. Remote Sens Environ 115(11):2798-2809

Pearse GD, Watt MS, Dash JP, Stone C, Caccamo G (2019) Comparison of models describing forest inventory attributes using standard and voxel-based lidar predictors across a range of pulse densities. Int J Appl Earth Obs Geoinf 78 $341-351$

Popescu SC, Zhao K (2008) A voxel-based lidar method for estimating crown base height for deciduous and pine trees. Remote Sens Environ 112(3):767-781

Popescu SC, Zhao K, Neuenschwander A, Lin C (2011) Satellite lidar vs. small footprint airborne lidar: comparing the accuracy of aboveground biomass estimates and forest structure metrics at footprint level. Remote Sens Environ 115(11):2786-2797

Qin YC, Yao W, Vu TT, Li SH, Niu Z, Ban YF (2015) Characterizing radiometric attributes of point cloud using a normalized reflective factor derived from small footprint LiDAR waveform. IEEE J Sel Topics Appl Earth Observ Remote Sens 8(2):740-749

Ramoelo A, Cho MA, Mathieu R, Madonsela S, van de Kerchove R, Kaszta Z, Wolff E (2015) Monitoring grass nutrients and biomass as indicators of rangeland quality and quantity using random forest modelling and world View-2 data. Int J Appl Earth Obs Geoinf 43:43-54

Ranson KJ Sun G, Kovacs K, Kharuk VI (2004) Landcover attributes from ICESat GLAS data in Central Siberia, IGARSS 2004. IGARSS2004 Proceedings, 20-24 September 2004, Anchorage, Alaska, USA

Richter K, Stelling N, Maas HG (2014) Correcting attenuation effects caused by interactions in the forest canopy in full-waveform airborne laser scanner data. ISPRS XL-3:273-280

Rogers JN, Parrish CE, Ward LG, Burdick DM (2015) Evaluation of field-measured vertical obscuration and full waveform lidar to assess salt marsh vegetation biophysical parameters. Remote Sens Environ 156:264-275

Silva CA, Saatchi S, Garcia M, Labriere N, Klauberg C, Ferraz A, Meyer V, Jeffery KJ, Abernethy K, White L, Zhao K, Lewis SL, Hudak AT (2018) Comparison of small- and large-footprint lidar characterization of tropical forest aboveground structure and biomass: a case study from Central Gabon. IEEE J Sel Topics Appl Earth Observ Remote Sens:11(10): 3512-3526

Solberg S, Hansen EH, Gobakken T, Næssset E, Zahabu E (2017) Biomass and InSAR height relationship in a dense tropical forest. Remote Sens Environ 192:166-175 
Stelling N, Richter K (2016) Voxel based representation of full-waveform airborne laser scanner data for forestry applications. ISPRS XLI-B8, pp 755-762

Stojanova D, Panov P, Gjorgjioski V, Kobler A, Džeroski S (2010) Estimating vegetation height and canopy cover from remotely sensed data with machine learning. Ecol Inform 5(4):256-266

Sumnall MJ, Hill RA, Hinsley SA (2016) Comparison of small-footprint discrete return and full waveform airborne lidar data for estimating multiple forest variables. Remote Sens Environ 173:214-223

Tsui OW, Coops NC, Wulder MA, Marshall PL (2013) Integrating airborne LiDAR and space-borne radar via multivariate kriging to estimate above-ground biomass. Remote Sens Environ 139:340-352

Wang ZS, Schaaf CB, Lewis P, Knyazikhin Y, Schull MA, Strahler AH, Yao T, Myneni RB, Chopping MJ, Blair BJ (2011) Retrieval of canopy height using moderateresolution imaging spectroradiometer (MODIS) data. Remote Sens Environ 115(6):1595-1601

Zhang WM, Wan P, Wang TJ, Cai SS, Chen YM, Jin XL, Yan GJ (2019) A novel approach for the detection of standing tree stems from plot-level terrestrial laser scanning data. Remote Sens 11(2):211

Zhao KG, Suarez JC, Garcia M, Hu TX, Wang C, Londo A (2018) Utility of multitemporal lidar for forest and carbon monitoring: tree growth, biomass dynamics, and carbon flux. Remote Sens Environ 204:883-897

Zheng G, Ma LX, Eitel JUH, He W, Magney TS, Moskal LM, Li MS (2017) Retrieving directional gap fraction, extinction coefficient, and effective leaf area index by incorporating scan angle information from discrete aerial Lidar data. IEEE Trans Geosci Remote Sens 55(1):577-590

Zhou Y, Qiu F (2015) Fusion of high spatial resolution WorldView-2 imagery and LiDAR pseudo-waveform for object-based image analysis. ISPRS 101:221-232

\section{Submit your manuscript to a SpringerOpen ${ }^{\circ}$ journal and benefit from:}

- Convenient online submission

- Rigorous peer review

- Open access: articles freely available online

- High visibility within the field

- Retaining the copyright to your article

Submit your next manuscript at $\boldsymbol{\nabla}$ springeropen.com 